\title{
Obesity on the wards, much more than weight management: descriptive characteristics of an obese cohort in a Dublin teaching hospital
}

\section{Abstract}

A study by Kent et al (Lancet Public Health, 2017), found a clear relationship between body weight and hospital admissions. In a recent observational study by Agarwal et al (Clinical Nutrition, 2018), one-in-three non-critically ill malnourished obese adults had poor food intake in hospital, and malnourished obese were least likely to receive nutrition support. The aim of this review was to describe the characteristics of obese inpatients referred to the dietitian and the range of nutritional care plans required. Data was collected retrospectively from dietetic records of inpatients with Body Mass Index (B.M.I.) $>35 \mathrm{~kg} / \mathrm{m}^{2}$, who were nutritionally assessed by the registered dietitian, in a 12 month period. Data included age, sex, weight, height, B.M.I. and length of stay, as well as diagnosis, comorbidities and their nutritional management. Institutional approval was obtained for this data review. 45 patients with B.M.I. $>35 \mathrm{~kg} / \mathrm{m}^{2}$ (30 men and 15 women) were referred to the dietitian during the time period, admitted under both medical (78\%) and surgical (22\%) specialities. Mean age was 58yrs (range 27-83yrs), mean BMI was $43 \mathrm{~kg} / \mathrm{m}^{2}$ (range $35-59.4 \mathrm{~kg} /$ $\mathrm{m}^{2}$ ), $55 \%$ were morbidly obese (BMI $>40 \mathrm{~kg} / \mathrm{m}^{2}$ ). Patients had multiple comorbidities requiring nutritional intervention to optimise management. 78\% had Diabetes Mellitus: $57 \%$ were on insulin. One third had renal impairment. One third had Congestive Cardiac Failure. $62 \%$ had respiratory complications, with $22 \%$ having spent time in intensive care. Following nutritional assessment, $78 \%$ required nutrition support to meet their nutritional requirements, of which $51 \%$ required nasogastric feeding and $86 \%$ were on oral nutritional supplements. Of patients requiring nutrition support, 63\% (22 patients) were also on a therapeutic diet, and $18 \%$ (8 patients) required texture modified diets. Of the patients not requiring nutrition support, $22 \%(\mathrm{n}=10): 15 \%$ received nutritional education regarding diabetes and only $7 \%$ received weight management advice as inpatients. Median length of stay was 14.5 days (range 4-193 days), compared to a mean length of stay for medical and surgical patients of 10 days and 7.1 days respectively. Obese inpatients are a complicated cohort, who typically present with multiple comorbidities. They can have complex, multifocal nutritional needs and may struggle to meet their nutritional requirements as inpatients, leading to unintentional weight loss in the acute setting. This review highlights the importance of screening obese patients for malnutrition risk, and the need for early referral to the dietitian for nutritional assessment and individualised nutrition care plans.

\section{Conflict of Interest}

There is no conflict of interest 